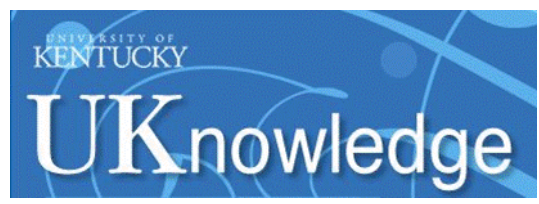

University of Kentucky

UKnowledge

\title{
SHAME AND BORDERLINE PERSONALITY FEATURES: THE POTENTIAL MEDIATING ROLE OF ANGER AND ANGER RUMINATION
}

Jessica R. Peters

University of Kentucky, jrpeters@gmail.com

Right click to open a feedback form in a new tab to let us know how this document benefits you.

\section{Recommended Citation}

Peters, Jessica R., "SHAME AND BORDERLINE PERSONALITY FEATURES: THE POTENTIAL MEDIATING ROLE OF ANGER AND ANGER RUMINATION" (2012). Theses and Dissertations--Psychology. 11. https://uknowledge.uky.edu/psychology_etds/11 accepted for inclusion in Theses and Dissertations--Psychology by an authorized administrator of UKnowledge. For more information, please contact UKnowledge@lsv.uky.edu. 


\section{STUDENT AGREEMENT:}

I represent that my thesis or dissertation and abstract are my original work. Proper attribution has been given to all outside sources. I understand that I am solely responsible for obtaining any needed copyright permissions. I have obtained and attached hereto needed written permission statements(s) from the owner(s) of each third-party copyrighted matter to be included in my work, allowing electronic distribution (if such use is not permitted by the fair use doctrine).

I hereby grant to The University of Kentucky and its agents the non-exclusive license to archive and make accessible my work in whole or in part in all forms of media, now or hereafter known. I agree that the document mentioned above may be made available immediately for worldwide access unless a preapproved embargo applies.

I retain all other ownership rights to the copyright of my work. I also retain the right to use in future works (such as articles or books) all or part of my work. I understand that I am free to register the copyright to my work.

\section{REVIEW, APPROVAL AND ACCEPTANCE}

The document mentioned above has been reviewed and accepted by the student's advisor, on behalf of the advisory committee, and by the Director of Graduate Studies (DGS), on behalf of the program; we verify that this is the final, approved version of the student's dissertation including all changes required by the advisory committee. The undersigned agree to abide by the statements above.

Jessica R. Peters, Student

Dr. Ruth A. Baer, Major Professor

Dr. David T. R. Berry, Director of Graduate Studies 
SHAME AND BORDERLINE PERSONALITY FEATURES:

THE POTENTIAL MEDIATING ROLE OF ANGER

AND ANGER RUMINATION

THESIS

A thesis submitted in partial fulfillment of the requirements for the degree of Master of Sciences in the College of Arts and Sciences at the University of Kentucky

By

Jessica R. Peters

Lexington, Kentucky

Director: Dr. Ruth A. Baer, Professor of Psychology

Lexington, Kentucky

2012

Copyright (C) Jessica R. Peters 2012 
ABSTRACT OF THESIS

\section{SHAME AND BORDERLINE PERSONALITY FEATURES: \\ THE POTENTIAL MEDIATING ROLE OF ANGER \\ AND ANGER RUMINATION}

Two prominent emotions in borderline personality disorder (BPD) are anger and shame. Rumination has been demonstrated to occur in response to shame and to escalate anger, and rumination, particularly anger rumination, has been shown to predict BPD symptoms. The present study examined whether one way that shame leads to the features of BPD is via increased anger and anger rumination. A sample of 823 undergraduates completed self-report measures of global and situational shame, traitlevel anger, anger rumination, and BPD features. A structural equation model was constructed using these measures. The hypothesized model of shame to anger and anger rumination to BPD features was largely supported. Bootstrapping was used to establish significant indirect effects from both forms of shame via anger rumination to BPD features, and from global shame via anger to BPD features. Recognizing this function of anger rumination may be important in developing and practicing interventions to reduce it. Further research into other ways individuals maladaptively respond to shame and functions of anger rumination is recommended.

KEYWORDS: Borderline Personality Disorder, Anger, Rumination, Shame, Structural Equation Modeling

Jessica R. Peters

July 5,2012 
SHAME AND BORDERLINE PERSONALITY FEATURES:

THE POTENTIAL MEDIATING ROLE OF ANGER

AND ANGER RUMINATION

By

Jessica R. Peters

Ruth A. Baer

Director of Thesis

David T. R. Berry

Director of Graduate Studies

July 5, 2012 


\section{TABLE OF CONTENTS}

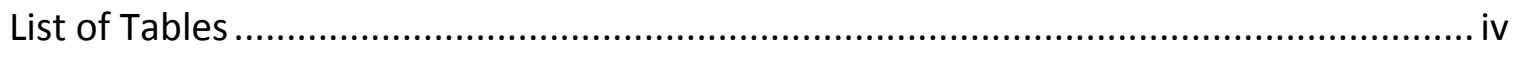

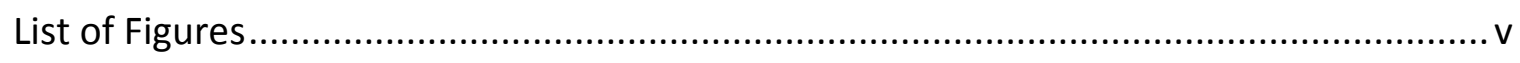

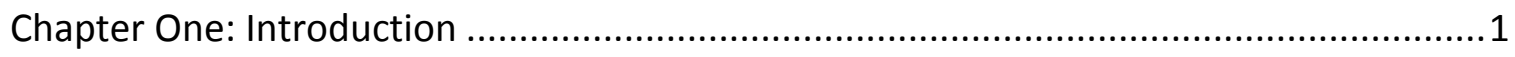

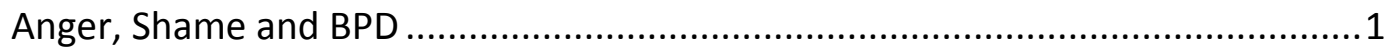

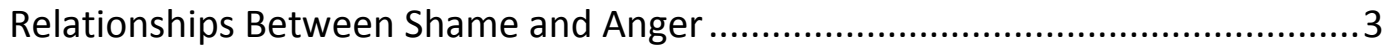

Rumination as a Response to Shame............................................................ 4

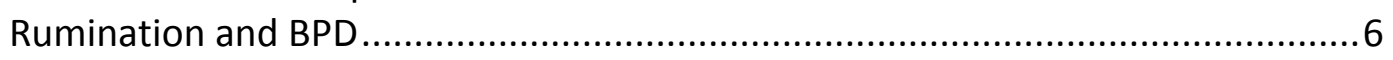

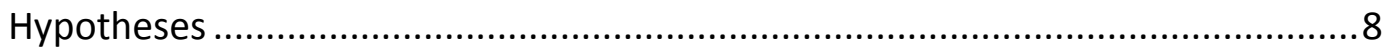

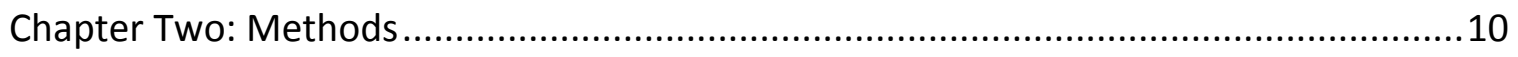

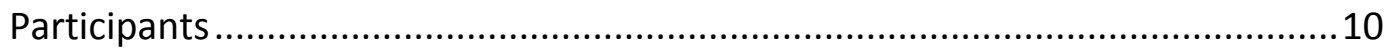

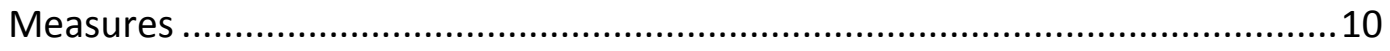

Borderline Features ............................................................... 10

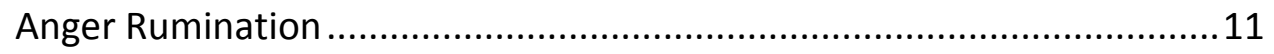

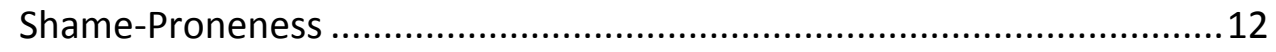

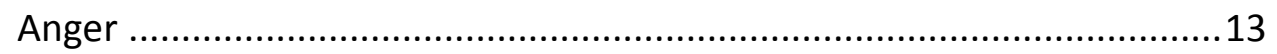

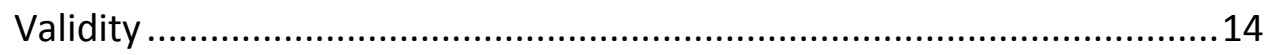

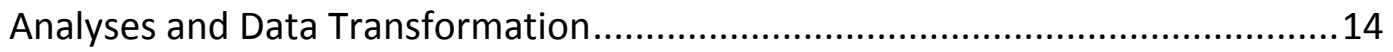

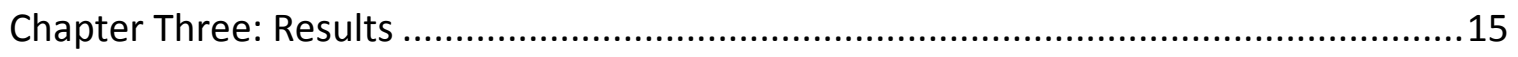

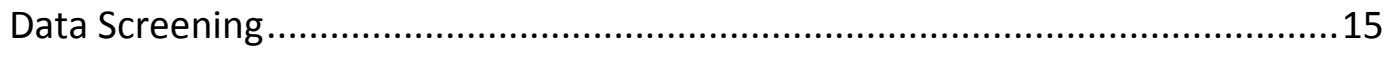

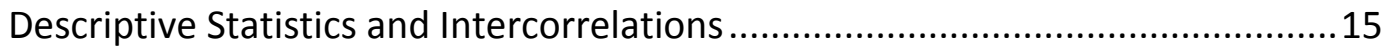

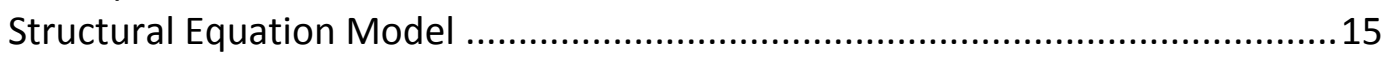

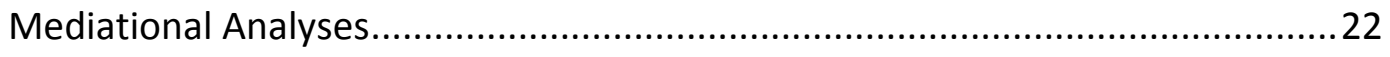

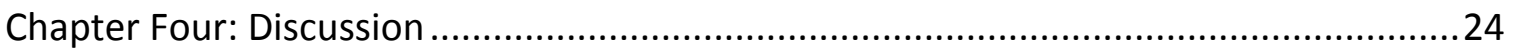

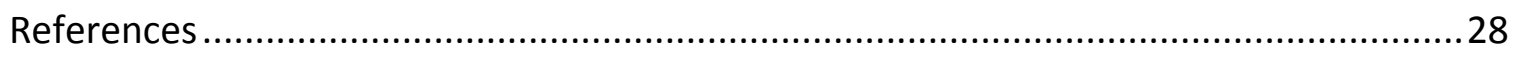

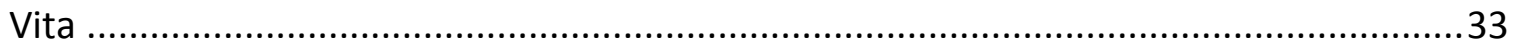




\section{LIST OF TABLES}

Table 3.1, Intercorrelations, Means and Standard Deviations (untransformed) for Study Variables... 16

Table 3.2, Standardized Effect Coefficients, Bias-Corrected Bootstrapped Confidence Intervals, and Effect Size (Percent of Total Effect) for Bootstrapped Indirect Effects of Shame via Anger and Anger Rumination on BPD Features 


\section{LIST OF FIGURES}

Figure 3.1, Measurement Models for Latent Shame Variables Used in Structural Model

Figure 3.2, Measurement Models for Latent Anger, Anger Rumination and BPD Variables Used in Structural Model.

Figure 3.3, Structural Model Predicting BPD Features from Shame via Anger and Anger

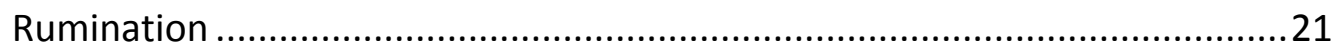




\section{Chapter One: Introduction}

Borderline personality disorder (BPD) is characterized by pervasive difficulties in emotion regulation, instability in interpersonal relationships, and maladaptive impulsivity across a number of domains (APA, 2000). Linehan (1993) proposes a transactional model in which biological predisposition interacts with an invalidating environment to produce BPD. The biological predisposition includes a high sensitivity to emotional stimuli, high emotional intensity, and a slow return to emotional baseline after emotions have been triggered. The baseline mood of most people with BPD is generally dysphoric. This mood is often punctuated by sudden shifts to intense fear or panic, shame, despair, or anger (APA, 2000). While the presence of these types of negative affect in BPD is well established, greater understanding is needed of how the dispositional tendency to experience these affective states leads to the difficulties characteristic of BPD, including further affective instability, identity disturbance, relationship problems and impulsive behavior.

\section{Anger, Shame and BPD}

Two of the most prominent emotions in BPD are anger and shame. The DSM-IVTR lists intense anger as a specific symptom of BPD (APA, 2000) that may lead to outbursts of verbal or physical aggression. Anger responses are more intense in BPD than healthy controls and last for longer durations of time (Jacob, 2008). Anger is the most common emotional antecedent to suicidal attempts reported by individuals with BPD (Chapman \& Dixon-Gordon, 2007). A twin study demonstrated support for a 
genetic underpinning for an increased tendency to experience anger in individuals with BPD, as well as environmental contributions to increased trait anger (Distel, 2011).

Although less emphasized in the DSM (APA, 2000), shame-proneness is widely believed to be characteristic of people with BPD (Linehan, 1993). A small literature suggests that people with BPD experience high levels of shame (Rüsch et al., 2007), and that shame predicts severity of symptoms associated with BPD, including self-harm (Brown, Linehan, Comtois, Murray, \& Chapman, 2009) and anger (Tagney, Wagner, HillBarlow, Marschall, \& Gramzow, 1996). Women with BPD report higher levels of shameproneness and state shame than women with social anxiety and healthy controls (Rusch, et al., 2007) and demonstrate greater increases in shame than normal or depressed controls in response to negative mood inductions (Jacob et al., 2009). Gratz, Rosenthal, Tull, and Lejuez (2010) found that individuals with BPD demonstrated significantly greater increases in shame following negative evaluation than non-BPD participants, and these elevations in shame persisted longer than other forms of negative affect. These findings are consistent with Linehan's (1993) biosocial theory that individuals with BPD experience more intense and longer-lasting negative emotions; however, these findings suggest that the slow return to baseline may be shame-specific. Linehan (1993) suggested that shame is a characteristic response to the experience of negative and uncontrollable emotions in people with BPD, and that this response is a natural result of an invalidating environment which criticizes or "shames" the child who expresses intense negative effect. Over time, the child learns to invalidate her own negative emotions and to feel shame whenever they arise, leading to high 
shame-proneness as an adult. Moreover, shame is common in victims of childhood sexual abuse (Edwall, Hoffman, \& Harrison, 1989), which is reported by many people with BPD.

While there is strong support for the relationship between shame-proneness and BPD, the mechanisms through which shame contributes to BPD features have not been established. The present study tests the role of anger and anger rumination as potential mediators of the relationship between shame-proneness and BPD features. Shame has been shown to predict anger, and anger rumination has been shown to lead to increases in negative affect and to be associated with dysregulated behavior that is common in BPD, including self-harm, substance misuse, and binge-eating.

\section{Relationships Between Shame and Anger}

While shame and anger have generally been studied independently in the context of BPD, several studies have demonstrated relationships between shame and anger in undergraduate samples. Shame-proneness predicted numerous aspects of anger and dysfunctional responses to anger, including anger arousal, hostility, a tendency to blame others for negative events, and negative long-term consequences in several student samples (Tangney, Wagner, Fletcher, \& Gramzow, 1992; Tangney, Wagner, \& Hill-Barlow, 1996). Lutwak, Parish, Ferrari and Razzino (2001) found that shame-proneness related to increased expressions of anger toward the self, but not outward expressed anger. Hejdenberg and Andrews (2011) demonstrated that this relationship between shame-proneness and anger is due to a more specific association between shame-proneness and the tendency to respond to criticism with anger. The 
association between shame and anger has also been demonstrated to be directional, from shame to anger, using longitudinal methods. Heaven, Ciarrochi and Leeson (2010) conducted a longitudinal study of the relationship between shame and hostility in adolescents using the PANAS-X shame and anger ratings, and found that higher levels of shame predict later increases in hostility, but that increases in hostility failed to predict later increases in shame.

Further research demonstrates that shame may explain the relationship between some forms of childhood maltreatment, anger, and dysfunctional behavior. In a sample of children with abusive and neglectful mothers, Bennett, Sullivan, \& Lewis (2005) found that while physical abuse did not demonstrate direct relationships with teacher-rated behavior problems, an indirect path via observer-rated shame and anger during a behavioral task was a significant predictor of externalizing behavior. Harper and Arias (2004) investigated these relationships in adults, finding that shame moderated the relationship between childhood maltreatment and current anger in men. That is, for men who had been maltreated as children, anger was higher in those with high levels of shame. In women, shame moderated the relationship between childhood maltreatment and depression.

\section{Rumination as a Response to Shame}

Rumination may be a mechanism through which negative affect is amplified in BPD. Rumination is a form of repetitive thought (Segerstrom, Stanton, Alden, \& Shortridge, 2003; Watkins, 2008) that can be conceptualized as a maladaptive form of emotion regulation. Response styles theory defines rumination as repetitively and 
passively focusing on symptoms of distress and possible causes and consequences of these symptoms. Individuals who engage rumination believe it to be necessary in order to gain insight about their problems and to find solutions for them (Lyubomirsky \& Nolen-Hoeksema, 1993; Papageorgiou \& Wells, 2001; Watkins \& Baracaia, 2001); however, rumination tends not to lead to active, problem-solving approaches (NolenHoeksema, Wisco, \& Lyubomirsky, 2008) and may intensify and prolong negative affect. Rumination has been demonstrated to occur in response to shame in individuals without psychopathology. Self-reported shame and rumination were significantly correlated in undergraduate samples, with rumination partially mediating the relationship between shame and depression (Cheung, Gilbert, \& Irons, 2004). In parents recently experiencing divorce, shame predicted depressive symptoms, and this relationship was mediated by self-reported rumination about distressing interactions (Orth, Burking, \& Burkhardt, 2006). Finkenauer and Rimé (1998) asked students to describe emotional events that they had experienced. One group was asked to choose an event that they had previously shared with others and the other to choose an event that they had kept private. Compared to shared events, emotional events that had been kept private were associated with greater shame and more rumination involving searching for meaning and understanding of what happened. Similar associations have also been found in clinical samples. Speckens, Ehlers, Hackman, Ruths, \& Clark (2007) interviewed individuals diagnosed with PTSD about recent experiences of intrusive memories (short, primarily sensory experiences) and rumination (longer lasting, 
primarily thought-based experiences). Feelings of shame were associated more with rumination than with intrusive memories.

Rumination has also been implicated in the escalation of anger. Peled and Moretti (2010) used self-report methods to examine rumination in response to both anger and sadness in a college sample and found support for anger rumination and depressive rumination as two distinct rumination subtypes, with anger rumination predicting aggression and depressive rumination predicting depressed mood. Anger rumination and anger were independently associated with aggression (Peled \& Moretti, 2010). Bushman, Bonacci, Pedersen, Vasquez, \& Miller (2005) found that undergraduate participants who ruminated after a minor annoyance displayed significantly greater levels of displaced aggression toward a confederate than participants who were distracted following the annoyance. Anger rumination may also facilitate the formation of distorted cognitions. Rusting and Nolen-Hoeksema (1998) demonstrated that responding with rumination to an angry mood resulted in increases in anger that did not occur after responding to the angry mood with distraction. These increases in angry mood were associated with more negative beliefs and associations incorporated into interpretations of ambiguous events.

\section{Rumination and BPD}

Because many of the negative outcomes associated with rumination are common in BPD, several authors have begun to investigate the role of rumination in BPD. Selby, Anestis and Joiner (2008) propose a cyclical process for emotion dysregulation in BPD termed the emotional cascades model, in which rumination 
creates a positive feedback loop that results in intense emotional responses to even minor emotional stimuli. The intensity of these emotions then leads to highly dysregulated behaviors, such as self-harm, substance use, binge-eating, and risky driving or sex, in order to distract attention from both the negative affect and the ruminative thoughts. In support of this model, Selby and Joiner (2009) found a significant association between the severity of BPD symptoms and rumination. They also reported that rumination mediated the relationship between BPD symptoms and dysregulated behavior, such as self-harm and binge-eating. Nolen-Hoeksema et al. $(2007 ; 2008)$ also suggest that maladaptive behaviors such as binge eating, substance use, and self-harm may function as ways to escape unpleasant ruminative states involving negative thoughts about the self (see also Heatherton \& Baumeister, 1991). This reciprocal relationship between negative affect, rumination, and dysregulated behaviors may explain rumination as a maintaining factor in the behavioral manifestations of BPD. Although depressive rumination has been found to be common in individuals with BPD (Abela, Payne, \& Moussaly, 2003; Smith, Grandin, Alloy, \& Abramson, 2006), rumination on anger appears to be more predictive of BPD symptoms. Baer and Sauer (2010) found that anger rumination, and, to a lesser extent, depressive rumination, significantly predicted BPD features above and beyond trait sadness, anger, and general negative affectivity. Anger rumination, but not depressive rumination, mediated the relationship between negative affectivity and BPD features in cross-sectional analyses (Baer \& Sauer, 2010). These findings were replicated by Upton, Peters, Eisenlohr-Moul, 
and Baer (under review), who found that of numerous forms of rumination, anger rumination demonstrated the strongest relationships with BPD features.

A recent review (Chapman, Dixon-Gordon, \& Walters, 2011) found that severity of BPD symptoms is positively associated with several forms of attempts to escape from or modify aversive internal experiences, including thought suppression, denial, selfdistraction, behavioral disengagement, and drug and alcohol abuse. Anger rumination has also been conceptualized as a method of avoiding internal experiences (Gardner \& Moore, 2008). Individuals prone to experiencing shame may find intense, self-directed negative affect difficult to tolerate and engage in efforts to avoid it. One way may be to engage in anger rumination, changing affect from inward-directed shame to externally directed anger and hostility by focusing on angering aspects of experiences. Anger, despite being generally conceptualized as negative affect, is approach oriented like some forms of positive affect (Harmon-Jones, Harmon-Jones, Abramson, \& Peterson, 2009). Focusing on anger may be reinforcing because it increases arousal and approach motivation. This argument is consistent with the findings of Tangney et al (1992) who suggest that the intense pain of shame, which involves a global denunciation of the self, leads to unfocused anger, which is quickly attributed to perceived unfairness in other people and situations. Ruminating about this anger functions as a way of avoiding the painful feelings of shame.

\section{Hypotheses}

First, the present study attempted to replicate previous research demonstrating that shame, anger, and anger rumination are associated with BPD features. All of these 
constructs were expected to demonstrate significant correlations with BPD features and with each other. A second aim of the study was to examine the role of anger rumination in the relationship between shame and BPD features. We predict that the tendency to engage in anger rumination will predict increased BPD features and hypothesized a significant indirect pathway from shame to anger rumination to BPD features. This indirect effect was predicted to be significant over and above effects of trait-level anger and to partially mediate the relationship between shame and BPD features.

Copyright @ Jessica R. Peters 2012 


\section{Chapter Two: Methods}

\section{Participants}

Participants were 925 undergraduate psychology students at the University of Kentucky who completed an online survey including demographics questions and a number of questionnaires (listed below, see Measures). Following data screening procedures (detailed in results section), a sample of 823 ( $85.9 \%$ white, $70.4 \%$ female) was used for analyses. Participants ranged in age from 18 to 59 with a mean age of 19.25 years $(S D=2.51)$. Participants received class credit for their participation.

Clinically significant BPD features have been shown to occur in the undergraduate population (Trull, 1995; Trull, 2001). Students with raw scores over 37 (T $=70$ ) on the Borderline Features Scale of the Personality Assessment Inventory (PAIBOR; Morey, 1991) demonstrate clinically significant BPD characteristics and levels of maladjustment similar to those in clinical populations. The use of a student sample in the present study allows investigation of the constructs of interest over a wide range of levels of BPD features, rather than at the extremes found in clinical samples. In the final sample of the present study, $11 \%$ of participants scored above $37(T=70)$ on the PAIBOR, indicating clinically significant BPD features.

\section{Measures}

Borderline Features. The Personality Assessment Inventory Borderline Features Scale (PAI-BOR; Morey, 1991) has 24 items measuring four aspects of BPD pathology: affective instability, identity problems, negative relationships, and self-harm. Elevated scores have been shown to differentiate BPD patients from those with other diagnoses, 
including anxiety, mood, and psychotic disorders, antisocial personality disorder, and substance abuse disorders (Morey, 1991). PAI-BOR scores also predicted academic and interpersonal functioning in a student sample after controlling for Axis I pathology and neuroticism (Trull, 1995; 1997). These findings suggest that high scores on the PAI-BOR are likely to reflect BPD-specific pathology rather than general distress or other disorders. In the present study, PAI-BOR subscales demonstrated adequate internal consistency $(\alpha=.71-81)$.

Anger Rumination. The Anger Rumination Scale (ARS; Sukhodolsky, Golub, \& Cromwell, 2001) has 19 items assessing the tendency to focus attention on angry moods, recall past anger episodes, and think about the causes and consequence of anger episodes. It has four subscales: angry afterthoughts; thoughts of revenge; angry memories; and understanding causes (e.g., "When something makes me angry I turn this matter over and over again in my mind"). Sukhodolsky et al. (2001) reported moderate correlations between ARS scores and anger-related constructs such as anger expression and suppressed anger. Factor analysis indicated that items representing anger constructs loaded on separate factors from the anger rumination items, which all loaded on a single factor, supporting the discriminant validity of anger rumination as distinct from anger. The ARS demonstrated excellent internal consistency in the present study $(\alpha=.92)$, the angry afterthoughts and angry memories demonstrated good internal consistency ( $\alpha=.81-.84)$ and the revenge and understanding causes subscales demonstrated adequate internal consistency $(\alpha=.72-.73)$. 
Shame-Proneness. Shame-proneness was assessed with two questionnaires.

Global shame was assessed with the Positive and Negative Affect Scale - Expanded Form (PANAS-X; Watson, Clark, \& Tellegen, 1988), a 60-item measure that asks respondents to rate their experiences of a variety of emotions on a 5-point Likert-style scale ( 1 = very slightly, $5=$ extremely). Multiple time frames can be used with this instrument; in the present study, participants were asked to rate their experiences of negative mood "in general," thus providing a measure of trait-level affect. The PANAS-X includes a "guilt" subscale with 6 items pertaining to both guilt and shame, including "ashamed," "angry at self," "disgusted with self," "blameworthy," "dissatisfied with self," and "guilty." The item "guilty" was excluded from the scale in the present study to create a scale more consistent with current definitions of "shame", as has been done in previous research (Brown, et al., 2009). The resulting PANAS shame subscale demonstrated good internal consistency in this sample $(\alpha=.87)$.

Situational shame was assessed with the Test of Self-Conscious Affect (TOSCA-3; Tangney \& Dearing, 2002), a scenario-based self-report instrument assessing shame, guilt, detachment and externalization. The scale uses 16 scenarios, including 11 negative events and 5 positive events; only responses to the negative events were analyzed for the present study. A sample scenario is as follows: "You attend your coworker's housewarming party and you spill red wine on a new cream-colored carpet, but you think no one notices." For each scenario, four possible reactions are presented; for this scenario: "You would wish you were anywhere but at the party" (indicating shameproneness); "You would stay late to help clean up the stain after the party" (guilt- 
proneness); "You think your coworker should have expected some accidents at such a big party" (detachment); and "You would wonder why your co-worker chose to serve red wine with the new light carpet" (externalization). All four reactions are rated from $1=$ not likely to $5=$ very likely, yielding sum scores between 11 and 55, with higher scores indicating a greater degree of proneness to that response. Only the shame scale in response to negative events was used in the present study, and it demonstrated adequate internal consistency $(\alpha=.76)$.

Anger. Trait-level anger was assessed with two measures. The anger subscale of the PANAS-X (see above for instrument description) contains six items, including "angry," "irritable," "loathing," "disgusted," "hostile," and "scornful" and demonstrated good internal consistency in the present sample $(\alpha=.82)$. The Buss Perry Aggression Questionnaire (AQ; Buss \& Perry, 1992) is a 29-item measure of anger, hostility, verbal aggression, and physical aggression. Participants are asked to rate statements about anger and aggression on a 7-point Likert-style scale $(1=$ extremely uncharacteristic of me, 5 = extremely characteristic of me). The present study used the anger subscale (ex: "Some of my friends think I'm a hothead") and the hostility subscale (ex: "I know that friends sometimes talk about me behind my back") were used in the present study as measures of the tendency to experience anger and to interpret situations and relationships in anger-consistent ways. Both subscales demonstrated good internal consistency in the present sample (Anger $\alpha=.86$; Hostility $\alpha=.89$ ). 
Validity. Two questions were included in the survey to check whether participants were attending to item and rating scale content. Each question asked the participant to select a specific answer that corresponded to one of the Likert scale options for the scale it was inserted into. The first question was inserted after the first third of the survey, and the second question was inserted in the last third of the survey. Analyses and Data Transformation

The results were analyzed using SPSS 19.0 and Mplus 6.11. All data were screened for skew and kurtosis in order to test assumptions of normality (Tabachnick \& Fidell, 2000). The PAI-BOR and ARS were skewed, and the PAI-BOR variables were corrected using square root transformation. Due to the number of analyses and the sample size, results were considered significant at a p-value of less than .01 .

Structuring equation modeling with Mplus 6.11 was used to test the model depicted in Figure 2. We hypothesized that shame would contribute to increased anger rumination, which would contribute to increased BPD features. The fit of the model was evaluated with standard criteria: non-significant chi-square statistic $\left(\chi^{2}\right)$, comparative fit index (CFI>.95), and root-mean-square-error of approximation (RMSEA <.08) (Hu \& Bentler, 1999). Reductions in akaike information criterion (AIC) values of 10 or more units were used to indicate significantly better fitting models (Burnham \& Anderson, 2004).

Copyright (C) Jessica R. Peters 2012 


\section{Chapter Three: Results}

\section{Data Screening}

Measures of interest for the analyses in the present study were presented in the first half of the study, so 79 participants who incorrectly answered the first validity question were removed. Remaining responses were screened for repeat participants (identified by duplicate ID numbers), responses in a straight line across measures, and obvious patterns, resulting in the exclusion of 23 additional participants. A final sample of 823 was used for analyses.

\section{Descriptive Statistics and Intercorrelations}

Table 3.1 presents descriptive statistics for the untransformed scores for all measures and intercorrelations among study measures. Consistent with the first hypothesis, all study measures demonstrated significant intercorrelations. With the exceptions of the BPD self-harm and the TOSCA shame scales, all correlations were large in magnitude. The PANAS shame scale demonstrated significantly greater associations with BPD features, anger, and anger rumination than the TOSCA shame scale $(t=4.30$ $8.73, p<.001)$. The two shame scales were only moderately intercorrelated, suggesting that while they are significantly associated, they may measure distinct forms or components of shame.

\section{Structural Equation Model}

Measurement models were fit for anger rumination, shame, and BPD features latent variables. The measurement model for anger rumination using the four 
Table 3.1. Intercorrelations, Means and Standard Deviations (untransformed) for Study Variables $(N=823)$

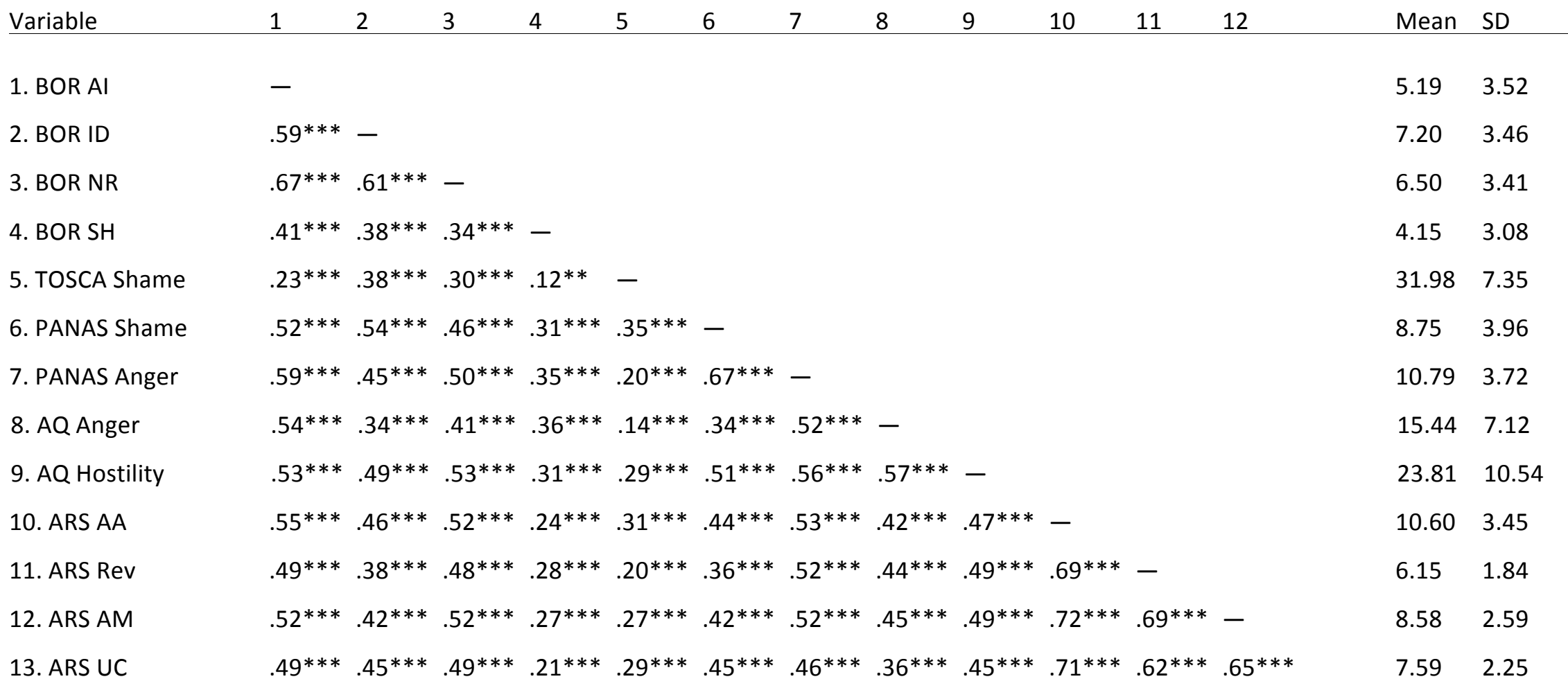

${ }^{* *} p<.01, * * * p<.001$

Note: BOR AI = Affective Instability; BOR ID = Identity Disturbances; BOR NR = Negative Relationships; BOR SH = Self Harm; TOSCA = Test of Self

Conscious Affect; PANAS = Positive and Negative Affect Scale; AQ = Aggression Questionnaire; ARS = Anger Rumination Scale, $A A=$ Angry

Afterthoughts, Rev $=$ Thoughts of Revenge, $\mathrm{AM}=$ Anger Memories, $\mathrm{UC}=$ Understanding Causes 
subscales of the ARS demonstrated good fit $\left(\chi^{2}=8.67, \mathrm{df}=2, p<.05 ; \mathrm{RMSEA}=.06, \mathrm{CFI}=\right.$ .99), with all four subscales loading significantly onto the latent variable $(.79-.87, p$ $<.001)$. The measurement model for an anger latent variable with loadings from the PANAS anger subscale, the AQ Anger subscale and the AQ Hostility subscale demonstrated excellent fit $\left(\chi^{2}=0.026, \mathrm{df}=1, p=.87\right.$; RMSEA $\left.=.00, \mathrm{CFI}=1.00\right)$, with all subscales loading significantly onto the latent variable $(.66-.68, p<.001)$.

A measurement model for a single shame variable was tested using loadings from both shame scales, with items from each scale parceled to create three indicators per scale. This model demonstrated poor fit $\left(\chi^{2}=422.11, \mathrm{df}=9, p<.001 ; \mathrm{RMSEA}=.26\right.$, $\mathrm{CFI}=.66)$. A latent variable for global shame was fit, with three parceled indicators. Two of the parcels contained two PANAS shame items each and one contained the single item "ashamed." The loadings for the two two-item parcels were constrained to be equal to enable identification, and the model demonstrated excellent fit $\left(\chi^{2}=1.50, d f=\right.$ $1, p=0.27 ; \mathrm{RMSEA}=.03, \mathrm{CFI}=1.00 ; \mathrm{AIC}=5008)$ with significant loadings from all indicators (.67-.90, $p<.001)$. A model was also fit using each PANAS shame scale item individually as an indicator; however, this model demonstrated worse fit to the data than the parceled model above $\left(\chi^{2}=76.88, \mathrm{df}=5, p<0.001 ; \mathrm{RMSEA}=.14, \mathrm{CFI}=0.96\right.$; AIC $=8526)$ and was not used. A latent variable for situational shame was modeled using only the TOSCA-3, parceled into 3 indicators, as a measure of situational shame. The situational shame latent variable model demonstrated excellent fit $\left(\chi^{2}=0.11, \mathrm{df}=1, p=\right.$ .11 ; RMSE $=.05, \mathrm{CFI}=0.99)$, with significant loadings from all indicators $(.69-.74, p<$ $.001)$. 

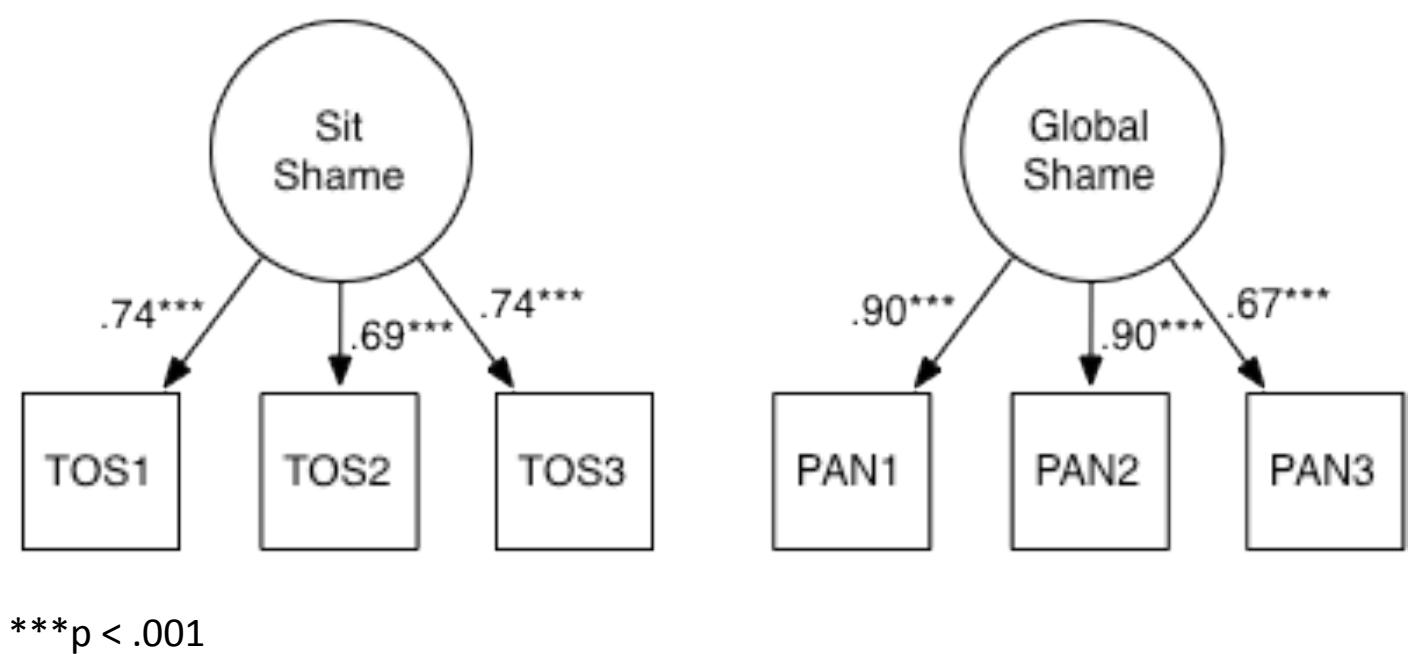

Figure 3.1. Measurement Models for Latent Shame Variables Used in Structural Model $(N=823)$.

Note: Sit Shame $=$ Situational Shame; TOS1, TOS2, TOS3 = Test of Self-Conscious Affect Shame scale parcels; PAN1, PAN2, PAN3 = Positive and Negative Affect Scale parcels. 


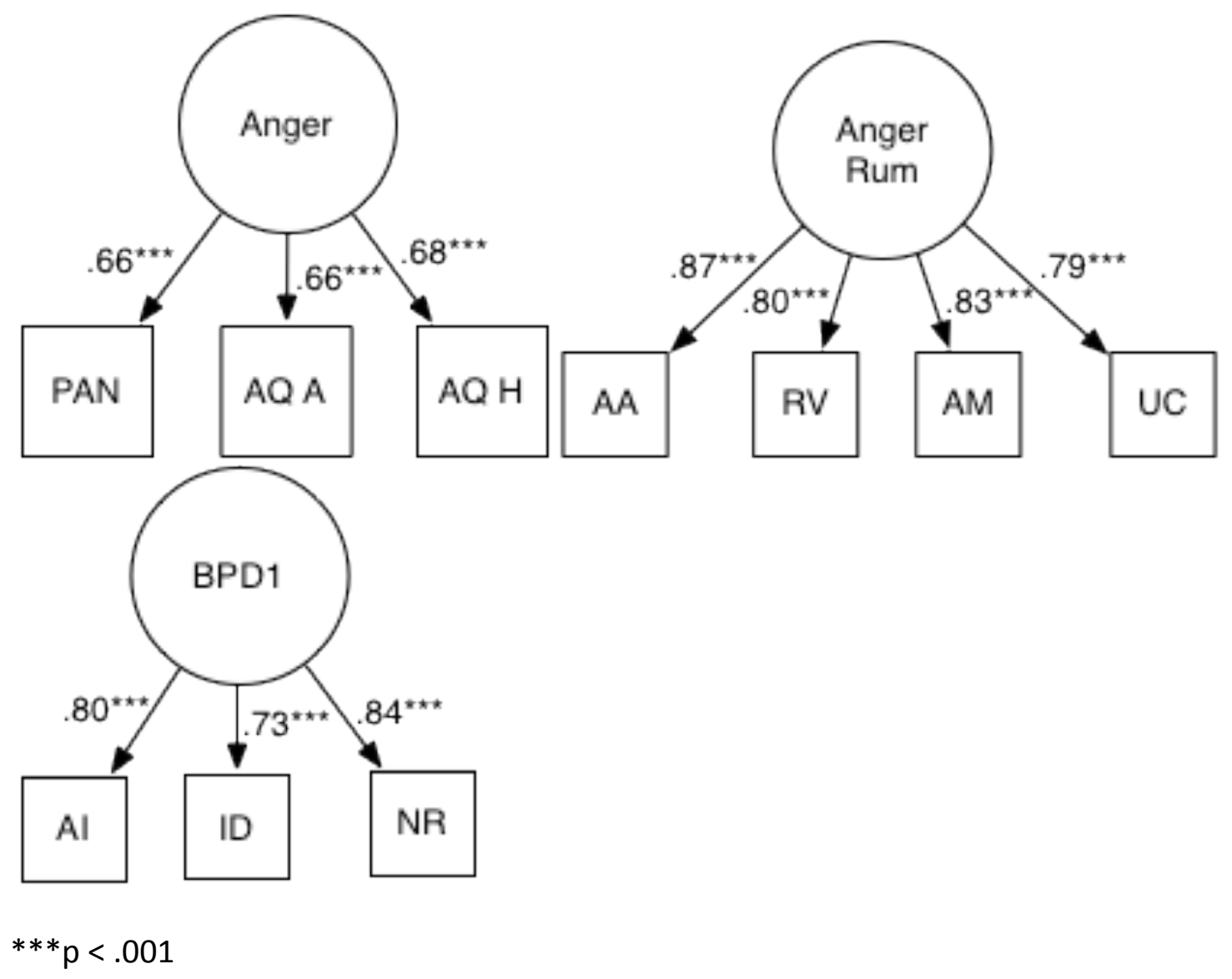

Figure 3.2. Measurement Models for Latent Anger, Anger Rumination and BPD Variables Used in Structural Model ( $\mathrm{N}=823)$.

Note: $\mathrm{PAN}=\mathrm{PANAS}$ anger scale; $\mathrm{AQ} \mathrm{A}=$ Aggression Questionnaire Anger scale; $\mathrm{AQ} \mathrm{H}=$ Aggression Questionnaire Hostility scale; AA = Anger Rumination Scale (ARS) Anger Afterthoughts; RV = ARS Revenge; AM = ARS Anger Memories; UC = ARS Understanding Causes; BPD = Borderline personality disorder; Al = Personality Assessment Instrument Borderline Features Scale (PAI-BOR) Affective Instability; ID = PAI-BOR Identity Disturbances; NR = PAI-BOR Negative Relationships. 
The measurement model for a single BPD features latent variable demonstrated good fit $\left(\chi^{2}=13.70, \mathrm{df}=2, \mathrm{p}=.001 ; \mathrm{RMSEA}=.08, \mathrm{CFI}=.99 ; \mathrm{AIC}=8134\right) ;$ however, the PAI-BOR self harm scale demonstrated lower loadings (.47) on the BPD latent variable than the other PAI-BOR subscales (.74-.82). This is consistent with findings in previous studies that the self-harm scale is less consistently related to other variables and endorsed to a lesser degree in student samples (Upton, Peters, Eisenlohr-Moul, \& Baer, under review); accordingly, a model was tested without the self-harm subscale. The single latent variable with the three remaining subscales, with loadings from $\mathrm{Al}$ and NR constrained to be equivalent, demonstrated excellent fit $\left(\chi^{2}=0.66, \mathrm{df}=1, p=0.42\right.$; RMSEA $=0.00 ; C F I=1.00 ; A I C=5979)$, and the reduction in AIC indicates significantly better fit than the model containing self-harm. All three subscales loaded significantly onto the latent variable $(.73-.84, p<.001)$. Accordingly, the self-harm scale was excluded from subsequent models.

A structural model (displayed in Figure 2) was fit with paths from situational and global shame to BPD features via anger and anger rumination. The model was an acceptable fit to the data $\left(\chi^{2}=350.96, d f=94, p<.001 ; \operatorname{RMSEA}=.06, \mathrm{CFI}=.96\right)$. Both forms of shame showed significant paths to anger rumination, but only global shame demonstrated a significant path to anger. Both anger and anger rumination demonstrated significant paths to BPD features. Situational shame also demonstrated a significant direct effect to BPD features; however, global shame did not. 


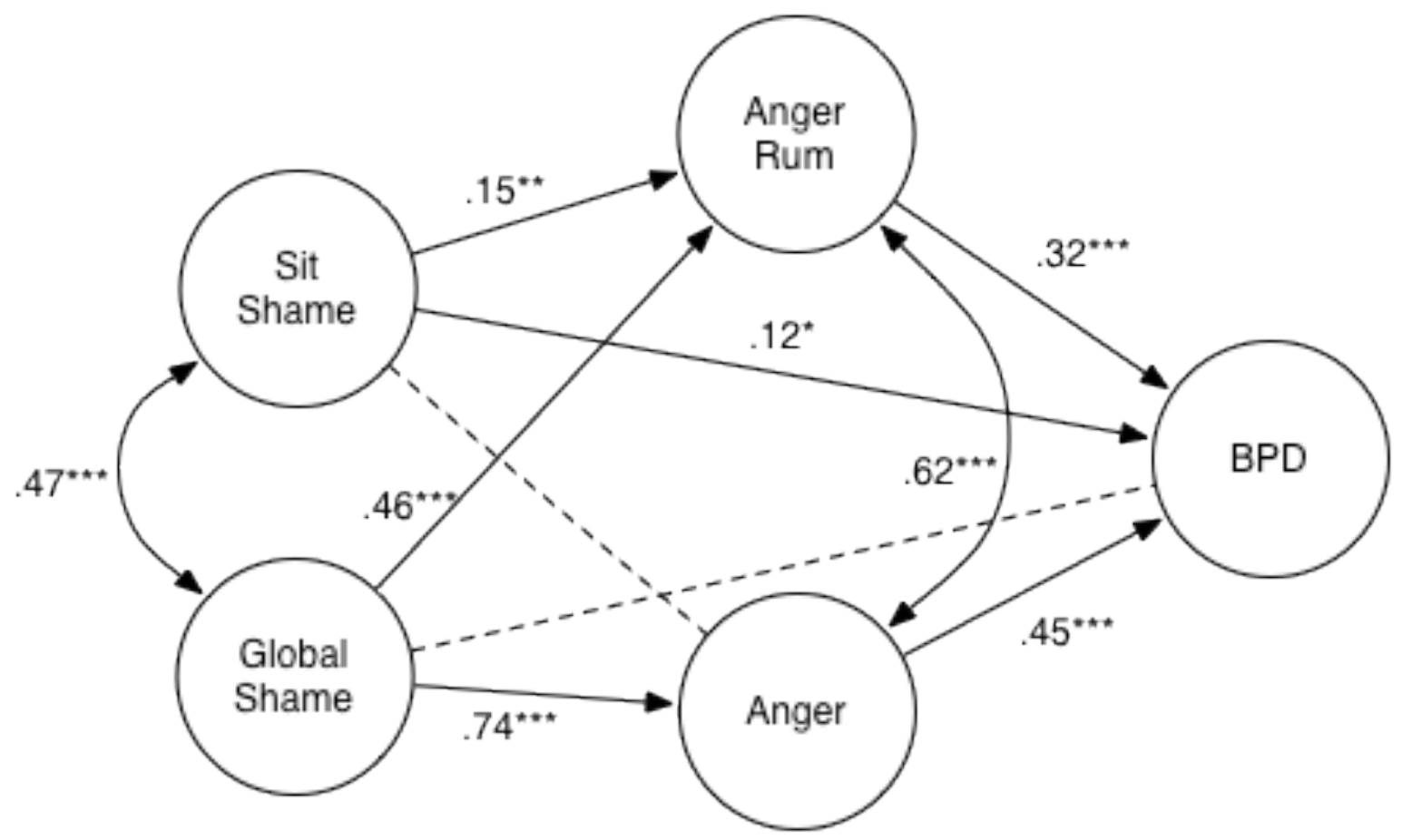

${ }^{*} p<.05, * * p<.01, * * * p<.001$

Figure 3.3. Structural Model Predicting BPD Features from Shame via Anger and Anger Rumination $(\mathrm{N}=823)$.

Note: Sit Shame $=$ Situational Shame. Anger Rum $=$ Rumination. BPD $=$ Borderline personality features. Non-significant paths are marked with dashed lines. 


\section{Mediational Analyses}

To test the mediational roles of anger and anger rumination in the relationship between shame and BPD features, indirect paths from situational and global shame to BPD features via anger and anger rumination were estimated. In order to test the significance of the indirect pathways, bootstrap analyses were conducted when fitting the structural model. Both $99 \%$ and $99 \%$ bias-corrected confidence intervals were generated using 1,000 bootstrap samples. Significant indirect effects were found from global shame via both anger and anger rumination to BPD features (see Table 3.2 for effect estimates, confidence intervals, and effect sizes for indirect paths). The combined indirect paths account for $83 \%$ of the effect of global shame on BPD features, with anger accounting for $57 \%$ and anger rumination for $26 \%$, fully mediating the relationship between global shame and BPD features. A significant indirect effect from situational shame via anger rumination to BPD features was also found; however, there was no significant indirect effect via anger. The indirect effect from situational shame via anger rumination was estimated to account for $33 \%$ of the total effect of situational shame on BPD, partially mediating the effect of situational shame on BPD features. These findings support the hypothesis that one of the ways both the tendency to experience shame in general and the tendency to respond to discrete situations with shame contribute to BPD symptoms may be through increased anger rumination. The combination of anger rumination and increased anger may account for the relationship between the tendency to experience shame more generally and BPD features. 
Table 3.2. Standardized Effect Coefficients, Bias-Corrected Bootstrapped Confidence Intervals, and Effect Size (Percent Of Total Effect) for Bootstrapped Indirect Effects of Shame via Anger and Anger Rumination on BPD Features $(N=823)$.

\begin{tabular}{lllll} 
& Estimate & $95 \% \mathrm{Cl}$ & $99 \% \mathrm{Cl}$ & $\%$ of Total \\
Effect & & & & \\
\hline Effects from Situational Shame & & & & \\
& & & \\
Total & $.15^{* *}$ & $.06-.24$ & $.03-.27$ & \\
& & & & \\
Total indirect & .03 & $-.05-.10$ & $-.07-.12$ & .20 \\
Indirect via Anger & -.02 & $-.09-.03$ & $-.07-.05$ & .13 \\
Indirect via Anger Rum & $.05^{*}$ & $.01-.08$ & $.00-.09$ & $.33^{*}$ \\
& & & & \\
Direct & $.12^{* *}$ & $.03-.21$ & $.01-.24$ & $.80^{* *}$ \\
Effects from Global Shame & & & & \\
Total & & & & \\
& & & & \\
Total indirect & $.58^{* *}$ & $.50-.65$ & $.47-.68$ & \\
Indirect via Anger & $.48^{* *}$ & $.35-.61$ & $.31-.65$ & $.83^{* *}$ \\
Indirect via Anger Rum & $.33^{* *}$ & $.17-.50$ & $.11-.56$ & $.57^{* *}$ \\
& $.15^{* *}$ & $.08-.22$ & $.06-.24$ & $.26^{* *}$ \\
Direct & .10 & $-.06-.25$ & $-.11-.30$ & .17 \\
& & & & \\
\hline$* p<.05, * * p<.01$ & & &
\end{tabular}

Copyright (C Jessica R. Peters 2012 


\section{Chapter Four: Discussion}

As predicted, shame-proneness, anger, anger rumination, and BPD features were significantly intercorrelated, although the strength and significance of the correlations with shame-proneness depended on the shame measure used. The PANAS, which asks participants to rate their global tendency to experience shame, demonstrated consistently stronger associations with anger, anger rumination, and BPD features than the TOSCA-3, which assess shame-consistent responses to negative situations. It may be that while individuals with BPD features do experience greater shame responses to stressful situations, the nature of the shame most associated with BPD features is a more general tendency to feel badly about the self.

The hypothesis that anger rumination would partially mediate the relationship between shame-proneness and BPD features was supported. Significant indirect paths were found from both global and situational shame via anger rumination to BPD features. These findings suggest that one way that shame may contribute to BPD features is via increased anger rumination. This finding supports the theory that Individuals experiencing high levels of shame may try to avoid or alter their affect by ruminating about anger. This response may be reinforcing in the short term, by increasing activation, similarly to types of positive affect (Harmon-Jones, et al., 2009), but also appears to increase vulnerability to affective instability, identity disturbances and negative relationships.

The improved fit of the BPD features latent variable without the self-harm subscale and the generally weaker correlations for this scale to other study constructs 
may be due to the lower mean value and potential restriction of range on that subscale in the present sample. Consistent with previous research examining BPD features in student samples (Upton, Peters, Eisenlohr-Moul, \& Baer, under review), self-harm was endorsed less than the other three BPD features scales. It may be necessary to use a clinical sample to examine this aspect of BPD features or to specifically oversample for individuals endorsing that subscale.

The tendency to respond to shame with anger rumination for individuals with BPD may explain the differences in magnitudes of associations between global shame scores and situational shame scores. When situations have the potential to elicit acute experiences of shame, individuals who tend to engage in anger rumination may ultimately experience more anger than shame, and thus may not associate as consistent or intense shame responses with specific, shame-inducing situations. Research has demonstrated paradoxical effects of suppressing or distracting from internal experiences however (Wegner, Schneider, Carter, \& White, 1987; Campbell-Sills, Barlow, Brown and Hoffman, 2006), so engaging in anger rumination may not prevent and even may ultimately increase more chronic, global feelings of shame. Further research into the nature of shame in BPD and longitudinal research into this potentially reciprocal relationship between shame, anger rumination and BPD features is needed.

Clinical implications of these findings include highlighting the importance of rumination in treating BPD. While ruminating about anger and other negative affect appears to exacerbate BPD symptoms, more mindful emotional processing, such as that taught through DBT skills training, may improve functioning by reducing rumination. 
Clinical research has demonstrated this effect: increases in emotional processing (attending to and thinking about one's emotions) were associated with less depression in a group of individuals receiving DBT, but associated with increases in depression in wait-list controls (Feldman, Harley, Kerrigan, Jacobo, \& Fava, 2009). The authors suggest that this pattern was seen because learning to process emotions with greater awareness and acceptance, as taught in DBT, is beneficial, whereas emotional processing in the form of rumination (which tends to be self-critical and unconstructive) may aggravate depression. Interventions that specifically target rumination, particularly anger rumination, may be further beneficial in reducing other types of BPD features, such difficulties in emotion regulation and interpersonal relationships. Acknowledging the function of anger rumination as distress-relieving in the short term may be important in encouraging individuals to attempt alternative responses to shame, given that they may experience more intense shame as they do so and require ways to tolerate that distress.

Although the findings in the present study provide preliminary support for the theory that responding to shame with anger rumination may increase risk for some BPD features, longitudinal research would allow a more conclusive test of mediation. Another important extension would be to examine these constructs with methods other than self-report. Experimental paradigms could be used to test whether inducing shame leads to more anger rumination and the subsequent dysregulated behavior characteristic of BPD. Another limitation of the present study is the use of a student sample that lacked a high percentage of individuals high in BPD features. Replicating and extending these findings in clinical samples would increase generalizability. 
Other future research directions could include examining potential moderators and further mediators that might explain which shame-prone individuals engage in this maladaptive response and provide additional areas for intervention. For example, distress tolerance might mediate the relationship between shame and experiential avoidance so that individuals high in distress tolerance do not attempt to avoid feelings of shame via anger rumination, whereas individuals low in distress tolerance do. This might be one avenue through which DBT, which has a distress tolerance skills module, increases functioning.

Copyright (C) Jessica R. Peters 2012 


\section{References}

American Psychological Association (2000). Diagnostic and Statistical Manual of Mental Disorders ( $4^{\text {th }}$ edition, text revision). Washington, DC: Author.

Abela, J. R. Z., Payne A. V. L., \& Moussaly N. (2003). Cognitive vulnerability to depression in individuals with borderline personality disorder. Journal of Personality Disorders, 17(4), 319-329.

Baer, R. A. \& Sauer, S. E. (2010). Relationships between depressive rumination, anger rumination, and borderline personality features. Personality Disorders: Theory, Research, and Treatment, 2(2), 142-150.

Bennett, D. S., Sullivan, M. W., Lewis, M. (2005). Young children's adjustment as a function of maltreatment, shame, and anger. Child Maltreatment, 10(4), 311323.

Berenson, K. R., Downey, G., Rafaeli, E., Coifman, K. G., \& Paquin, N. L. (2011). The rejection-rage contingency in borderline personality disorder. Journal of Abnormal Psychology, 120, 681-690.

Brown, M. Z., Linehan, M. M., Comtois, K. A., Murray, A., \& Chapman, A. L. (2009). Shame as a prospective predictor of self-inflicted injury in borderline personality disorder: a multi-modal analysis. Behavior Research and Therapy, 47, 815-822.

Burnham, K. P. \& Anderson, D. R. (2004). Multimodel inference: Understanding AIC and $\mathrm{BIC}$ in model selection. Sociological Methods Research, 33, 261-304.

Bushman B. J., Bonacci, A. M., Pedersen, W. C., Vasquez, E. A., \& Miller N., (2005). Chewing on it can chew you up : Effects of rumination on triggered displaced aggression. Journal of Personality and Social Psychology, 88(6), 969-983.

Buss, A. H., \& Perry, M. P. (1992). The aggression questionnaire. Journal of Personality and Social Psychology, 63, 452-459.

Campbell-Sills, L., Barlow, D. H., Brown, T. A., \& Hofmann, S. G. (2006). Effects of suppression and acceptance on emotional responses on individuals with anxiety and mood disorders. Behavior Research and Therapy, 44, 1251-1263.

Cardaciotto, L., Herbert, J. D., Forman, E. M., Moitra, E., \& Farrow, V. (2007). The assessment of present-moment awareness and acceptance. Assessment, 15(2), 204-223.

Chapman, A. L. \& Dixon-Gordon, K. L. (2007). Emotional antecedents and consequences of deliberate self-harm and suicide attempts. Suicide and Life-Threatening Behavior, 37(5), 543-552.

Chapman A. L., Dixon-Gordon, K. L., \& Walters, K. N. (2011). Experiential avoidance and emotion regulation in borderline personality disorder. Journal of RationalEmotive \& Cognitive-Behavior Therapy, 29(1), 35-52. 
Cheung, M. S. P., Gilbert, P., \& Irons, C. (2004). An exploration of shame, social rank and rumination in relation to depression. Personality and Individual Differences, 36(5), 1143-1153.

Distel, M. A., Roeling, M. P., Tielbeek, J. J., van Toor, D., Derom, C. A., Trull, T. J., \& Boomsma, D. I. (2011). The Covariation of Trait Anger and Borderline Personality: A Bivariate Twin-Siblings Study. Journal of Abnormal Psychology. Advance online publication. doi: 10.1037/a0026393

Edwall, G. E., Hoffmann, N. G., \& Harrison, P. A. (1989). Psychological correlates or sexual abuse in adolescent girls in chemical dependency treatment. Adolescence, 24(94) 279-288.

Feldman, G., Harley, R., Kerrigan, M., Jacobo, M., \& Fava, M. (2009). Change in emotional processing during a dialectical behavior therapy-based skills group for major depressive disorder. Behaviour Research and Therapy 47(4), 316-321.

Finkenauer, C. \& Rimé, B. (1998) Socially shared emotional experiences vs. emotional experience kept secret: Differential characteristics and consequences. Journal of Social and Clinical Psychology, 17(3), 295-318.

Gardner, F. L. \& Moore Z. E. (2008). Understanding clinical anger and violence. Behavior Modification, 32(6), 897-912.

Gratz, K. L., Rosenthal, M. Z., Tull, M. T., \& Lejuez, C. W. (2010). An experimental investigation of emotional reactivity and delayed emotional recovery in borderline personality disorder: the role of shame. Comprehensive Psychiatry, $51,275-285$.

Harmon-Jones, E., Harmon-Jones, C., Abramson, L., \& Peterson C. K. (2009). PANAS positive activation Is associated with anger. Emotion, 9(2), 183-196.

Harper, F. W. K., \& Arias I. (2004). The role of shame in predicting adult anger and depressive symptoms among victims of child psychological maltreatment. Journal of Family Violence, 19(6), 359-367.

Hayes, S. C., Wilson, K. G., Gifford, E. V., Folette, V. M., \& Strosahl K. (1996). Experiential avoidance and behavioral disorders: a functional dimensional approach to diagnosis and treatment. Journal of Consulting and Clinical Psychology, 64(6), 1152-1168.

Heatherton, T. F. \& Baumeister R. F. (1991). Binge eating as escape from self-awareness. Psychological Bulletin, 110(1), 86-108.

Heaven, P. C. L., Ciarrochi J., \& Leeson, P. (2010). Parental styles and religious values among teenagers: a 3-year prospective analysis. The Journal of Genetic Psychology, 171(1), 93-99.

Hejdenberg, J. \& Andrews,B. (2011). The relationship between shame and different types of anger: A theory-based investigation. Personality and Individual Differences, 50(8), 1278-1282. 
Hu, L. \& Bentler, P. M. (1999). Cutoff criteria for fit indexes in covariance structure analysis: Conventional criteria versus new alternatives. Structural Equation Modeling, 6, 1-55.

Jacob, G. A., Cindy, G., Zimmermann, S., Corinna, N. S., Rüsch, N., Rainer, L., Nerb, J., Lieb, K. (2008). Time course of anger and other emotions in women with borderline personality disorder: A preliminary study. Journal of Behavior Therapy and Experimental Psychiatry, 39(3), 391-402.

Jacob, G. A., Hellstern, K., Ower, N., Pillman, M., Scheel, C. N., Rüsch, N., \& Lieb, K. (2009). Emotional reactions to standardized stimuli in women with borderline personality disorder: Stronger negative affect, but no differences in reactivity. The Journal of Nervous and Mental Disease, 197(11), 808-815.

Linehan, M. (1993). Cognitive-behavioral treatment of borderline personality disorder. New York: Guilford Press.

Lutwak, N., Panish, J. B., Rerrari, J. R., \& Razzino, B. E. (2001). Shame and guilt and their relationship to positive expectations and anger expressiveness. Adolescence, 36(144), 641-653.

Lyubomirsky, S., \& Nolen-Hoeksema, S. (1993). Self-perpetuating properties of dysphoric rumination. Journal of Personality and Social Psychology, 65(2), 339349

Morey, L. C. (1991). Personality Assessment Inventory Professional Manual. Odessa, FL: Psychological Assessment Resources, Inc.

Nolen-Hoeksema, S., Wisco, B. E., \& Lyubomirsky S. (2008) Rethinking Rumination. Perspectives on Psychological Science, 3(5) 400-424.

Nolen-Hoeksema, S., Stice, E., Wade, E., \& Bohon, C. (2007). Reciprocal relations between rumination and bulimic, substance abuse, and depressive symptoms in female adolescents. Journal of Abnormal Psychology, 116(1), 198-207.

Orth, U., Burking, M., Burkhardt, S. (2006). Self-conscious emotions and depression: rumination explains why shame but not guilt is maladaptive. Personality and Social Psychology Bulletin, 32(12), 1608-1619.

Papageorgiou, C. \& Wells, A. (2001) Metacognitive beliefs about rumination in recurrent major depression. Cognitive and Behavioral Practice, 8(2), 160-164.

Peled, M. \& Moretti, M. M. (2010). Rumination on Rumination: are Rumination on Anger and Sadness Differentially Related to Aggression and Depressed Mood? Journal of Pathology and Behavioral Assessment, 32(1), 108-117.

Rüsch, N., Lieb, K., Göttler, I., Hermann, C., Schramm, E., Richter, H., Jacob, G. A., Corrigan, P. W., \& Bohus, M. (2007). Shame and implicit self-concept in women with borderline personality disorder. American Journal of Psychiatry, 164(3), 500-508. 
Rusting, C. L., Nolen-Hoeksema, S. (1998). Regulating responses to anger: effects of rumination and distraction on angry mood. Journal of Personality and Social Psychology, 74(3), 790-803

Segerstrom, S. C., Stanton, A., L., Alden L. E., \& Shortridge, B. E. (2003). A multidimensional structure for repetitive thought: What's on your mind, and how, and how much? Journal of Personality and Social Psychology, 85(5), 909921.

Selby, E. A., Anestis, M. D., \& Joiner T. E. (2008). Understanding the relationship between emotional and behavioral dysregulation: Emotional cascades. Behaviour Research and Therapy, 46(5), 593-611.

Selby E. A. \& Joiner T. E. (2009). Cascades of emotion: The emergence of borderline personality disorder from emotional and behavioral dysregulation. Review of General Psychology, 13(3), 219-229.

Smith, J. M., Grandin, L. D., Alloy, L. B., \& Abramson, L. Y. (2006). Cognitive vulnerability to depression and Axis II personality dysfunction. Cognitive Therapy and Research, 30(5), 609-621.

Speckens, A. E. M., Ehlers, A., Hackman, A., Ruths, F. A., \& Clark, D. M. (2007). Intrusive memories and rumination in patients with post-traumatic stress disorder: $A$ phenomenological comparison. Memory, 15(3), 249-257.

Sukhodolsky, D. G., Golub, A., \& Cromwell, E. N. (2001). Development and validation of the anger rumination scale. Personality and Individual Differences, 31, 689-700.

Tabachnick \& Fidell (2000). Using Multivariate Statistics. Allyn \& Bacon, $4^{\text {th }}$ Edition.

Tangney, J. P. \& Dearing, R. L. (2002). Shame and Guilt. NY: Guilford Press.

Tangney, J. P., Wagner, P. E., Fletcher, C., \& Gramzow, R (1992). Shamed into anger? The relation of shame and guilt to anger and self-reported aggression. Journal of Personality and Social Psychology, 62(4), 669-675.

Tangney, J. P., Wagner, P. E., Hill-Barlow D., Marschall, D. E., \& Gramzow, R. (1996). Relation of shame and guilt to constructive versus destructive responses to anger across the lifespan. Journal of Personality and Social Psychology, 70(4), 797-809.

Trull, T. J. (1995). Borderline personality disorder features in nonclinical young adults: I. Identification and validation. Psychological Assessment, 7(1), 33-41.

Trull, T. J., Useda, D., Conforti, K., \& Doan, B. (1997). Borderline personality disorder features in nonclinical young adults: 2 . Identification and validation. Journal of Abnormal Psychology, 106(2), 307-314.

Trull, T. J. (2001). Structural relations between borderline personality disorder features and putative etiological correlates. Journal of Abnormal Psychology, 110(3), 471481. 
Upton, B. T., Peters, J. R., Eisenlohr-Moul, T. \& Baer, R. A. (under review). Ruminative thought in individuals with borderline personality disorder features.

Watson, D., Clark, L. A., \& Tellegen, A. (1988). Development and validation of brief measures of positive and negative affect: the PANAS scales. Journal of Personality and Social Psychology, 54(6), 1063-1070.

Wegner, D. M.., Schneider, D. J., Carter III, S. R. \& White, T. L. (1987). Paradoxical effects of thought suppression. Journal of Personality and Social Psychology, 53, 5-13. 


\section{JESSICA R. PETERS \\ VITA \\ Department of Psychology \\ University of Kentucky}

Place of Birth: Los Angeles, California

Date of Birth: April 15, 1981

\section{EDUCATION}

University of Massachusetts Boston, Boston, MA

B.S. in Psychology, Summa cum Laude

Date of Completion: June 2007

\section{HONORS \& AWARDS}

Research Challenge Trust Fund Fellowship, University of Kentucky, 2011-2012

Certificate for Outstanding Teaching, University of Kentucky, 2011

Daniel R. Reedy Quality Achievement Fellowship, University of Kentucky, 2009-2012

\section{PUBLICATIONS}

Peters, J.R., Upton, B.T., \& Baer, R.A. (in press). Relationships between facets of impulsivity and borderline personality features. Journal of Personality Disorders.

Baer, R.A, Peters, J.R., Eisenlohr-Moul, T.A., Geiger, P.J., \& Sauer, S.E. (2012). Emotionrelated cognitive processes in borderline personality disorder: A review of the empirical literature. Clinical Psychology Review, 32, 359-369.

Baer, R.A., Lykins, E.L.B., \& Peters, J.R. (2012). Mindfulness and self-compassion as predictors of psychological wellbeing. Journal of Positive Psychology, 7, 230-238.

Peters, J.R., Erisman, S.M., Upton, B.T., Baer, R.A., \& Roemer, L. (2011). A preliminary investigation of the relationships between dispositional mindfulness and impulsivity. Mindfulness, 2, 228-235.

Baer, R.A. \& Peters, J.R. (2011) Assessment of acceptance and mindfulness in behavioral medicine. In: McCracken, L. M. (Ed.), Acceptance and Commitment Therapy and Mindfulness-based Approaches in Behavioral Medicine: An Integrative Clinical and Research Guide. Oakland, CA: New Harbinger Publications.

Peters, J.R., Vallie, B., Difronzo, M. \& Donaldson, S.T. (2007). Role of dopamine D1 receptors in novelty seeking in adult female Long-Evans rats, Brain Research Bulletin, 74, 232-236. 
Research Assistant, Center for Drug Abuse Research Translation

2011-Present

2010-Present

2009-2011

2007-2009
Chrysalis House, Lexington, $\mathrm{KY}$

Student Therapist

Jesse G. Harris Psychological Services Center, University of Kentucky

Therapist

Department of Psychology, University of Kentucky

Teaching Assistant

Cambridge Health Alliance, Cambridge, MA

Research Coordinator 